\title{
Erratum to: Phenological response of Nitraria tangutorum to climate change in Minqin County, Gansu Province, northwest China
}

\author{
Jianhui Du • Ping Yan • Yuxiang Dong • Fugiu Han
}

Published online: 18 June 2010

(C) ISB 2010

\section{Erratum to: Int J Biometeorol DOI 10.1007/s00484-010-0315-3}

The following author should be added to the list of authors for this article:

Fugui Han, Minqin National Studies Station for Desert Steppe Ecosystem, Gansu Desert Control Research Institute, Lanzhou, 730070, China, e-mail: hanfug2008@126.com

The author's would also like to correct the Acknowledgements so that it now reads:

This study was supported by State Key Laboratory of Earth Surface Processes and Resource Ecology (2008-ZZ-
02), Open Fund Program by Gansu Key Laboratory of Desertification Combating (KD200602), and the Key Technologies R\&D Program of China (2006BAD 26B0302, 2007BAC30B05). Thanks are due to Prof. Youhao E of National Meteorological Information Center, China, for providing the daily rainfall data and Doctor Miaogen Shen for valuable suggestions to our manuscript. The authors would also like to thank the editor and referees for their useful and constructive suggestions and comments.

The online version of the original article can be found at http://dx.doi. org/10.1007/s00484-010-0315-3.

\footnotetext{
J. Du

College of Resources Science \& Technology,

Beijing Normal University,

Beijing 100875, China

e-mail: dujh1982@hotmail.com

P. Yan $(\square)$

State Key Laboratory of Earth Surface Processes and Resource

Ecology, Beijing Normal University,

No.19, Xinjiekouwai Street,

Beijing 100875, China

e-mail: yping@bnu.edu.cn

Y. Dong

School of Geographical Science and Planning,

Sun Yat-Sen University,

Guangzhou 510275, China

e-mail: eesdyx@mail.sysu.edu.cn

F. Han

Minqin National Studies Station for Desert Steppe Ecosystem,

Gansu Desert Control Research Institute,

Lanzhou 730070, China

e-mail: hanfug2008@126.com
} 